\title{
To Analyze the Yield and Price Uncertainties in the Production of Bottle Gourd on Contract and Non-Contract Farms
}

\author{
Arjun Singh Rajput ${ }^{*}$, Harkesh Kumar Balai ${ }^{2}$, Vikalp Sharma ${ }^{2}$ and R.C. Sharma ${ }^{3}$ \\ ${ }^{1}$ SKN collage of agriculture, Jobner Jaipur, India \\ ${ }^{2}$ Department of Agricultural economics and management RCA, MPUAT Udaipur, India \\ ${ }^{3}$ Department of Agricultural Economics SKN, Jobner, Jaipur, India \\ *Corresponding author
}

\section{A B S T R A C T}

The present investigation was undertaken with a view to studying the yield and price

Keywords

Contract farming,

Gross income,

Contract farms,

Contract farms, Price

uncertainty

uncertainties involved in the production of bottle gourd under contract farming of bottle gourd in the Jaipur district of Rajasthan. The contracting firm ROCL Ltd. was selected, as it was only contracting firm in the Bassi tehsil which was engaged in the contract farming related to cucurbits and other vegetables. A list of 26 villages having contract farming in bottle gourd was obtained from the tehsil headquarter. From that list three villages were selected randomly. From these villages, 30 contract farmers were selected randomly and 20 non-contract farmers resembling to the contract farmers except contract component were also selected to make a comparative study of the contract farming vis-à-vis non-

Article Info

Accepted:

22 July 2018

Available Online:

10 August 2018 contract farming. Primary data were collected for the agricultural year 2015-16. The conventional budgeting technique and multiple regression functions were used to analyze the data. The production and price uncertainty ratio and coefficient of variation were lower on contract farms than that on non-contract farms indicating that the uncertainty on contract farms was less as compared to non-contract farms.

\section{Introduction}

India with vegetable production of 146.55 million tonnes is the second largest producer of vegetables contributing $14 \%$ of world's vegetable production. With an area of 8.5 million hectares under vegetables, the average productivity of vegetables in India is $17.3 \mathrm{t} / \mathrm{ha}$ in 2010-11. Percentage share of vegetable production in the major vegetable growing states in India are West Bengal (18.2), Uttar Pradesh (12.1), Bihar (10), Andhra Pradesh (8.1), Gujarat (6.4), Karnataka (6.2), Tamil
Nadu (5.6), Odisha (5.3), Maharashtra (5.1), Haryana (3.2) and others (19.8). An area, production and productivity of Rajasthan are 1.4 million ha, 10.719 tonnes and $6.3 \mathrm{t} / \mathrm{ha}$, respectively (Vegetable Statistics - IVRI (2010-2011). There are many big corporate houses such as Hindustan lever, Pepsi foods, A.V. Thomas, Daburs, Thapars, Marico, Godrej, Mahindra Sulabh, Nijjer agro food Ltd., Wimco, SAB Miller India, ROCL Ltd., etc. that undertake contract farming for many crops apart from several players. ROCL Ltd. entered in the production and marketing of 
vegetables, fruits and flowers. Among vegetables it cultivate cabbage, cauliflower, strawberry, olive, tomato, squash green/yellow, chilli, watermelon, bottle gourd, cucumber, etc. under contract farming in the state on 19.04.2007 under the Company Act 1956.The company was constituted in collaboration with the Government of Rajasthan through Rajasthan State Agriculture Marketing Board, Plastro Plasson Industries (India) Limited (now Finolex Plasson Industries (India) Limited), Pune \& Indolive Limited of Israel having equal partnership. Initially, the Government of Rajasthan through Rajasthan State Agriculture Marketing Board \& Plastro Plasson Industries (India) Limited, Pune.

\section{Materials and Methods}

\section{Selection of the study area and crop}

In Jaipur district contract farming in case of cucurbits was prevalent only in three tehsils namely Bassi, Jhotwara and Shahpura. Among these three tehsils, Bassi tehsil occupies first place in area and production of bottle gourd. Therefore, bottle gourd and bassi tehsil were selected purposively as study crop and study area, respectively.

\section{Sampling procedure}

Multi stage stratified random sampling technique was used for drawing a sample for the present study. At first stage of sampling, the block in the district was selected. At the second stage of sampling, the villages in the block were selected. At the third stage of sampling, the wheat growers were selected as respondents.

\section{Selection of the villages}

A list of 26 villages having contract farming in bottle gourd was obtained from the tehsil headquarter. From that list three villages namely Dhindon, Damodarpura and Kacholiya were selected randomly.

\section{Selection of the farmers}

A list of 127 bottle gourd growers was prepared with the help of supervisor.

Out of 127 bottle gourd growers, 57 were contract and 70 were non-contract farmers.

From that list 50 farmers were selected randomly. Out of 50 farmers, 30 farmers were contract and 20 were non-contract.

\section{Selection of the contracting firm}

The contracting firm ROCL Ltd. was selected, as it was only contracting firm in the Bassi tehsil which was engaged in the contract farming related to cucurbits and other vegetables.

\section{Collection of data}

Primary data were collected for the study. The primary data in respect of cost of cultivation, cost of production, returns from bottle gourd, marketing costs and margins of bottle gourd crop were collected from the producer farmers, contracting firm, wholesalers-cumcommission agents and retailers through personal interview method with the help of a pretested schedule specifically prepared (standardized) for the purpose.

\section{Analysis of data}

After collection, the data were compiled, tabulated and analyzed according to the selected categories of sample farms.

Mainly tabular analysis was done and simple averages, percentages, standard deviation and coefficient of variation were calculated. 


\section{Uncertainty in production and price}

The very nature of farm enterprises entails some uncertainties in their production and prices coupled with uncertainties in availability of inputs. There were two approaches used to analyze the data. First, measuring in terms of uncertainty ratios and second, in terms of coefficient of variation.

\section{Uncertainty ratio}

The yield uncertainty ratio (YUR) and price uncertainty ratio (PUR) were calculated as follows:

Average highest expected yield -

Average lowest expected yield Yield uncertainty ratio $($ YUR $)=$

Average expected yield

Average highest expected price Average lowest expected price Price uncertainty ratio $(\mathrm{PUR})=$

$$
\text { Average expected price }
$$

The expected yield was estimated by multiplying yield with its probability of occurrence on the farmer's fields. The expected yield which was lowest taken to be the lowest expected yield and the highest as the highest expected yield.

These expected yields so obtained were summed up and their average was calculated by dividing the sum with the number of farmers in each category.

The expected price was also estimated by same process as expected yield.

\section{Coefficient of variation}

For measuring yield and price uncertainties standard deviation and coefficient of variation were calculated as follows:

\section{Standard deviation}

The standard deviation (S.D.) measures the absolute dispersion of variability of distribution. Here mean and standard deviation were used for measurement of coefficient of variation.

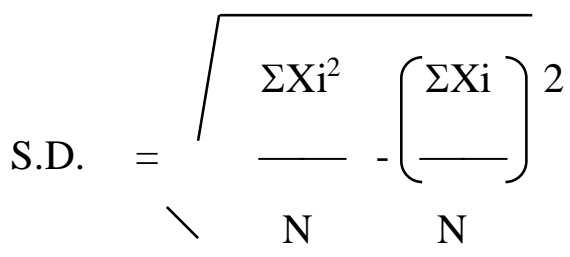

Where,

$\Sigma \mathrm{Xi}^{2}=$ Sum of squares of the variable

$\Sigma \mathrm{Xi}=$ Sum of values of the variables

$\mathrm{N}=$ Number of farmers

\section{Coefficient of variation}

C.V. $(\%)=\frac{\text { Standard deviation }}{\text { Arithmetic mean }}$

\section{Results and Discussion}

This section deals with the production and price uncertainties of bottle gourd on contract and non-contract farms in the Jaipur district of Rajasthan.

Here two measures or approaches were used for measuring the uncertainty: First, uncertainty ratio measure and second, coefficient of variation.

\section{Uncertainty ratio approach}

Under this approach production and price uncertainties in terms of uncertainty ratios of bottle gourd on contract and non-contract farms were analyzed and discussed under the following sub heads: 


\section{Production uncertainty}

Table 1 depicts the production uncertainty in terms of uncertainty ratio of bottle gourd on different categories of contract and noncontract farms.

The table 1 indicates that overall production uncertainty ratio on contract as well as on noncontract farms was worked out at 0.05 and 0.07 , respectively. It was lower by 0.02 on contract farms than that on non-contract farms. It indicates that the production uncertainty ratio on contract farms was less as compared to non-contract farms.

Category-wise production uncertainty ratio varied from 0.04 on large farms to 0.07 on small farms on contract farms. In case of noncontract farms production uncertainty ratio varied from 0.04 on large farms to 0.07 on small farms. Category-wise production uncertainty decreased with the increase in the size group of farms on contract and noncontract farms. Category-wise differential production uncertainty ratio on contract farms over non-contract farms was estimated to be highest on small farms (0.03) followed by medium (0.02), large (0.01) with an overall difference of 0.02 . These findings were in conformity with Olesen (2003).

\section{Price uncertainty}

Category-wise price uncertainty in terms of price uncertainty ratio of bottle gourd on contract and non-contract farms is depicted in table 1 .

The table 1 indicates that overall price uncertainty ratio on contract farms was at 0.07 and that on non-contract farms 0.08 being slightly higher on non-contract farms. It indicates that the price uncertainty ratio on contract farms was less as compared to noncontract farms. Category wise price uncertainty ratio varied from 0.05 on large farms to 0.08 on small farms on contract farms. In case of non-contract farms price uncertainty ratio varied from 0.08 on large farms to 0.11 on small farms. Category wise price uncertainty decreased with the increase in the size group of farms on contract and noncontract farms.

Table.1 Uncertainty ratio approach

Production uncertainty

\section{Category of farm}

\section{Contract farms}

(i) Average highest expected yield

(ii) Average lowest expected yield

(iii) Average expected yield

(iv) Uncertainty Ratio

\section{Non-contract farms}

(i) Average highest expected yield

(ii) Average lowest expected yield

(iii) Average expected yield

(iv) Uncertainty Ratio

Difference in uncertainty ratio over contract farms
Farm size

Smal

186.37

174.10

181.68

0.07

169.73

154.10

162.29

0.10

0.03
Medium

202.14

191.33

196.26

0.06

196.18

182.05

187.43

0.08

0.02
Large

213.56

204.70

209.64

0.04

211.67

202.30

207.87

0.05

0.01
192.53

179.48

Overall

200.69

190.04

195.86

0.05

185.86

0.07

0.02 
Price uncertainty

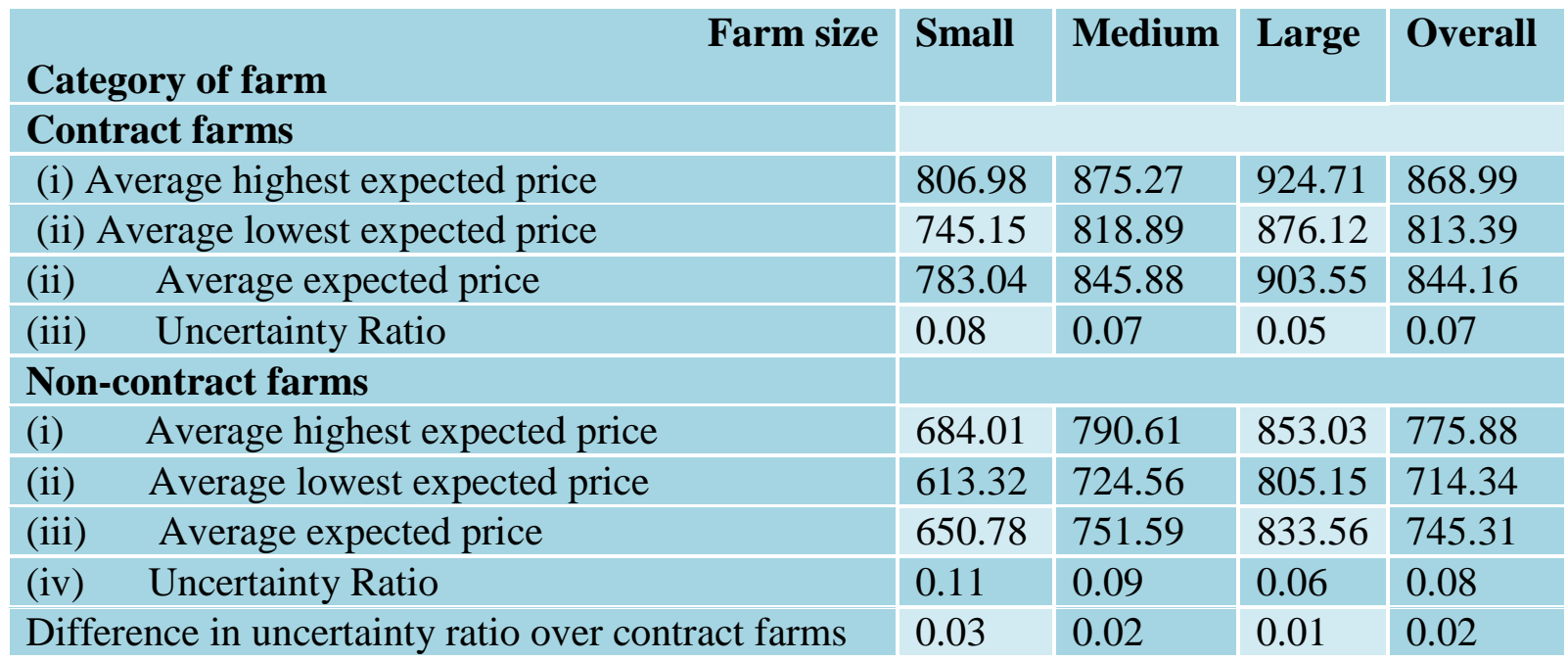

Coefficient of variation approach

Production uncertainty

\begin{tabular}{|c|c|c|c|c|}
\hline Category of farm & Small & Medium & Large & Overall \\
\hline \multicolumn{5}{|l|}{ Contract farms } \\
\hline (i) Mean (q) & 181.68 & 196.26 & 209.64 & 195.86 \\
\hline (ii) SD (q) & 6.19 & 4.93 & 4.65 & 3.92 \\
\hline (iii) $\mathrm{CV}$ (per cent) & 3.41 & 2.51 & 2.22 & 2.00 \\
\hline \multicolumn{5}{|l|}{ Non-contract farms } \\
\hline (i) Mean (q) & 162.29 & 187.43 & 207.87 & 185.86 \\
\hline (ii) $\mathrm{SD}(\mathrm{q})$ & 7.82 & 7.13 & 4.71 & 6.53 \\
\hline (iii) $\mathrm{CV}$ (per cent) & 4.82 & 3.80 & 2.27 & 3.51 \\
\hline Difference in uncertainty ratio over contract farms & 1.41 & 1.30 & 0.05 & 1.51 \\
\hline
\end{tabular}

Price uncertainty

\begin{tabular}{|c|c|c|c|c|}
\hline Category of farm & Small & Medium & Large & Overall \\
\hline \multicolumn{5}{|l|}{ Contract farms } \\
\hline (i) Mean (₹ per q) & 783.04 & 845.88 & 903.55 & 844.16 \\
\hline (ii) SD (q) & 31.18 & 28.20 & 24.36 & 27.85 \\
\hline (iii) $\mathrm{CV}$ (per cent) & 3.98 & 3.33 & 2.70 & 3.30 \\
\hline \multicolumn{5}{|l|}{ Non-contract farms } \\
\hline (i) Mean $(₹$ per q) & 650.78 & 751.59 & 833.56 & 745.31 \\
\hline (ii) $\mathrm{SD}$ (q) & 35.37 & 33.21 & 24.16 & 30.77 \\
\hline (iii) $\mathrm{CV}$ (per cent) & 5.43 & 4.42 & 2.90 & 4.13 \\
\hline Difference in uncertainty ratio over contract farms & 1.45 & 1.08 & 0.20 & 0.83 \\
\hline
\end{tabular}


Category wise difference on non-contract farms over contract farms was estimated to be highest on small (0.03) followed by medium (0.02) and small farms (0.01) with an overall difference of 0.02 . These findings were in confirmity with Tripathi et al., (2005) and Dileep et al., (2002).

\section{Coefficient of variation approach}

Under this approach uncertainties in case of coefficient of variation of production and price of bottle gourd on contract and noncontract farms were analyzed by estimating coefficients of variation and discussed under the following sub heads:

\section{Production uncertainty}

In order to assess the extent of uncertainty involved in the production of bottle gourd, the measures of standard deviation (SD) and coefficient of variation (CV) were worked out and presented in table 1 .

The table 1 indicates that overall $\mathrm{CV}$ on contract farms was 2.00 per cent and that on non-contract farms 3.51 per cent. It indicates that the production uncertainty on contract farms was less as compared to non-contract farms. Category wise CV varied from 2.22 per cent on large farms to 3.41 per cent on small farms on contract farms. In case of noncontract farms it varied from 3.51 per cent on large farms to 4.82 per cent on small farms.

Category wise production uncertainty decreased with the increase in the size group of farms on contract and non-contract farms. The difference in production uncertainty on non-contract farms over contract farms was estimated to be highest on small farms (1.41 per cent) followed by medium (1.30 per cent) and large farms ( 0.05 per cent) with an overall difference of 1.51 per cent. These findings were in confirmity with Kalamkar (2005).

\section{Price uncertainty}

The table 1 depicts the category-wise price uncertainty in terms of $\mathrm{CV}$ of bottle gourd on contract and non-contract farms in the state of Rajasthan.

The table 1 indicates that overall $\mathrm{CV}$ on contract and on non-contract farms was worked out at 3.30 per cent and 4.13 per cent, respectively. It indicates that the price uncertainty on contract farms was less as compared to non-contract farms. Category wise CV varied from 2.70 per cent on large farms to 3.98 per cent on small farms on contract farms. In case of non-contract farms it varied from 2.90 per cent on large farms to 5.43 per cent on small farms. Category wise price uncertainty decreased with the increase in the size group of farms on contract and non-contract farms. The difference in $\mathrm{CV}$ for prices on non-contract farms over contract farms was estimated to be highest on small farms (1.45 per cent) followed by medium ( 1.08 per cent $)$ and large farms $(0.20$ per cent $)$ with an overall difference of 0.83 per cent. From the above discussion it may be concluded that the production and price uncertainties in bottle gourd were less on contract farms probably because of adoption of better cultural practices by the producer farmers from the time of sowing to harvesting, coupled with uses of quality seeds, investments made in farm assets.

These findings were in conformity with Dileep et al., (2002), Arka and Sayili (2005), Kalamkar (2005) and Tripathi et al., (2005). As against this, non-contract farms particularly used local varieties of seeds, along with low level of input use and low investment and fluctuation in market price. Category wise production and price uncertainties decreased with the increase in the size group of farms on contract and noncontract farms. 


\section{References}

Arka, H. and Sayili, M. (2005), Risk and Uncertainty (Variability) in Wheat Production in Turkey. Journal of Applied Sciences, 5 (1); 101-103.

Dileep, B.K., Grover, R.K. and Rai, K.N., (2002), Contract Farming of Tomato: An Economic Analysis. Indian Journal of Agricultural Economics, 57 (2); 197 210.

Kalamkar, S.S., (2005), Contract Farming in India: Progress, Possibilities and
Constraints. Indian Journal of Agricultural Marketing, 19 (2); 164165.

Olesen, H.B., (2003), Contract Production of Peas. Food Policy, 28 (1); 29-50.

Tripathi, R.S., Singh, R. and Singh, S., (2005), Contract Farming in Potato Production: An Alternative for Managing Risk and Uncertainty. Agricultural Economics Research Review, 18 (Conference No.); 47-60.

\section{How to cite this article:}

Arjun Singh Rajput, Harkesh Kumar Balai, Vikalp Sharma and Sharma, R.C. 2018. To Analyze the Yield and Price Uncertainties in the Production of Bottle Gourd on Contract and NonContract Farms. Int.J.Curr.Microbiol.App.Sci. 7(08): 4215-4221. doi: https://doi.org/10.20546/ijcmas.2018.708.441 